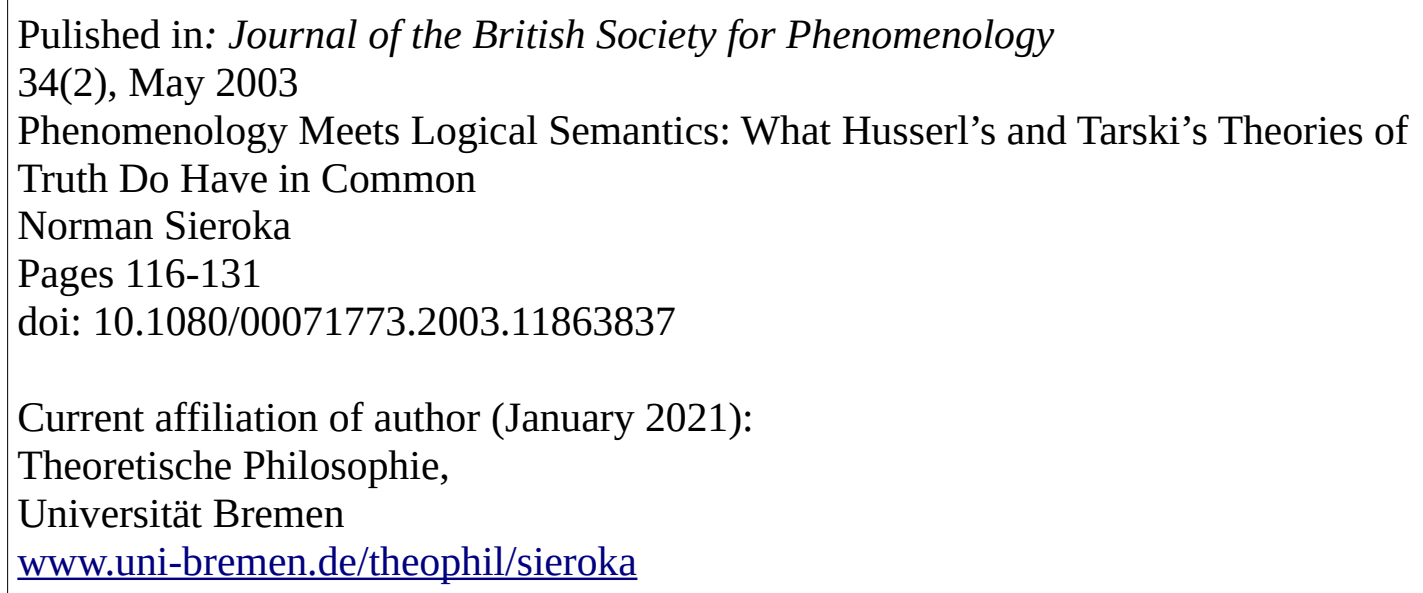

\begin{abstract}
The aim of this paper is to draw out some connections between phenomenology and logical semantics in respect of the theory of truth. Jan Wolenski has discussed several continuities from Brentano to Tarski and this paper is a further development of his approach. ${ }^{1}$ Wolenski's account fails to take Husserl into consideration and I shall argue here that a comparison between Husserl and Tarski proves to be a particularly fruitful means of drawing out the commonalities between phenomenology and logical semantics; commonalities that concern the idea of philosophy as a formal, scientific enterprise, the notion of self-evidence and the bringing about of Aristotle's programme of a theory of truth. Of central importance is the concept of 'Erfüllung' ('fulfilment', 'satisfaction'), which is used by both Husserl and Tarski. Once this concept is properly understood, it is possible to see how much the two theories have in common and how the term 'correspondence', when applied to these accounts, is somewhat misleading. Finally, the philosophical significance of the parallels drawn gets discussed.
\end{abstract}

\title{
Phenomenology Meets Logical Semantics: What Husserl's and Tarski's Theories of Truth Do Have in Common
}

\author{
Norman Sieroka
}

Keywords:

Brentano, fulfilment (Erfüllung), Husserl, self-evidence, Tarski, theory of truth

\section{Introduction}

At first glance, the views of phenomenologists like Brentano and Husserl seem to have nothing to do with logical semantics as advocated by Tarski. Particularly in the theory of truth, which is the subject matter of this essay, there seems to be very little in common

1 Wolenski (1997). 
between those traditions. Husserl holds that a meaning intention becoming an actual experience is true if it gets fulfilled, i.e. if it finds an instantiation in a self-evident judgement. ${ }^{2}$ For Tarski, in contrast, sentences are true only if they satisfy the following kind of equivalence: 'The sentence <it is snowing> is true if and only if it is snowing.' But, as I shall show, there are a lot of parallels, parallels which will show that Tarski is quite far away from being a straightforward analytic philosopher, and which will shed some light on the highly disputed issue of whether Tarski holds a correspondence theory. ${ }^{3}$ Before going into more detail, however, let me briefly introduce the historical connections between phenomenology and logical semantics. This is important because it shows the common academic background of those two traditions. It also indicates at which philosophers one should look if one wants to show continuities between phenomenology and logical semantics (which is my aim here).

It is well known that Franz Brentano (1838-1917) strongly influenced both experimental psychology and phenomenology - here in particular Edmund Husserl (1859-1938). ${ }^{4}$ Not so well known, however, is his influence on Polish philosophy. When Brentano taught in Vienna, Kazimierz Twardowski (1866-1938) became one of his pupils. Twardowski worked on the difference between content and object of psychological phenomena, and his work became important for both psychologists and phenomenologists. ${ }^{5}$ He left Vienna in 1895 and became a professor in Lvov (Poland). His pupils there included Jan Lukasiewicz (1878-1956), the founder of the first manyvalued logic, and Stanislaw Lesniewski (1886-1939), who worked on the foundations of mathematics. Lesniewski became famous for his extended propositional calculus, called 'protothetic', and for his 'intuitionistic formalism', something I have more to say about later. Lukasiewicz and Lesniewski both became professors in Warsaw and together with two other Twardowski pupils, Tadeus Kotarbinski (1886-1981) and Kazimierz Ajdukiewicz (1890-1963), they formed the first generation of what has since been called the Lvov-Warsaw School. Alfred Tarski (1901-1983) grew up in this academic background when he came to Warsaw in the 1920s.

Let us have a look at Tarski's theory of truth in more detail now (section 2), pick up certain characteristics of it one by one and discuss them against the philosophical background just given (sections 3 to 5). Here, of course, the contributions of someone like Kotarbinski on Tarski's philosophy are well known (Tarski dedicated Logic, Semantics, Metamathematics to Kotarbinski, calling him his teacher). Thus, when looking at Tarski's academic background we should focus on the less well investigated contributions by Brentano and Husserl. Not only will this help to understand certain features of Tarski's theory that seem quite strange otherwise, but also it will show an almost natural development from phenomenology to semantics (section 6).

2 See Husserl (1968), Vol 3, pp. 115-27.

3 The most famous philosophers who engaged in that issue are presumably Popper in his Logik der Forschung and Davidson in his Inquiries into Truth and Interpretation.

4 See for example 'Vorwort' and 'Einleitung' to Brentano (1973), Vol 1, pp. xii, lxxxvii \& xciii; 'Einleitung' to Brentano (1974), passim; Albertazzi et al. (1996), p.8; Mulligan \& Smith (1985), passim.

5 See Sajama \& Kamppinen (1987), pp. vi \& 42-50; ‘Einleitung’ to Twardowski (1982), p. xix. 


\section{Tarski's Theory of Truth}

Statements like 'The sentence <it is snowing > is true if and only if it is snowing.' are the basis of Tarski's semantic theory of truth, whereby the expression '<it is snowing>' denotes 'it is snowing'. Here we must distinguish the language in which the definition of truth is given (the metalanguage) from the language for which the definition of truth holds (the object language). These languages have to fulfil the following criterion:

(Cr) The metalanguage must be logically essentially richer than the object language. ${ }^{6}$

This means that more must be expressible in the metalanguage than in the object language. Logically this can be done, for instance, by the metalanguage containing variables of a higher type. Besides other things, this prevents semantic paradoxes like the 'Liar paradox' from being stated.'

Any statement like 'The sentence <it is snowing > is true if and only if it is snowing.' is only a partial definition of truth. For even if we know whether ' $<$ it is snowing >' is true or not, we know nothing about '<swans are white $>$ ' or '<armchairs are cosy $>$ yet. To get a general theory of truth in a given language, we need all the statements of the type 'The sentence $<\mathrm{X}>$ is true if and only if $\mathrm{X}$ '. Truth (as opposed to 'truths') then becomes the class of all true sentences. One cannot, however, state all those sentences, for there are infinitely many of them. Therefore Tarski gives a recursive definition in terms of sentential functions. Sentential functions (other than sentences) allow for free variables which we need to give a recursive definition. Here is an example: '( $x$ ) . Fx v Gx' (read: 'for all $x$ : $F$ of $x$ or $G$ of $x$ ') is a sentence which one would like to define recursively as made up by ' $F x$ ', ' $G x$ ' and by using the operation of disjunction and general quantification. But, ' $F x$ ' and ' $G x$ ' are not sentences, they are sentential functions. The latter, however, can be defined recursively.

The possibility suggests itself, however, of introducing a more general concept which is applicable to any sentential function, can be recursively defined, and, when applied to sentences, leads us directly to the concept of truth. These requirements are met by the notion of the satisfaction of a given sentential function by given objects [...]. ${ }^{8}$

For reasons that will become clear in section 5, we should have a look at the German version of the last sentences: '[...] diesen Bedingungen genügt nämlich der Begriff des Erfülltseins der gegebenen Aussagefunktion durch gegebene Gegenstände [...]'. ${ }^{9}$ Thus,

6 Tarski fails to give this criterion at the beginning, but during the investigation it turns out to be a necessary and sufficient condition for establishing truth - cf. Tarski (1983d), p. 406; Tarski (1944), p. 352.

7 The 'Liar paradox'is the paradox that occurs if one wonders whether one is saying the truth by saying 'I am lying.' But, since essentially more can be expressed in the metalanguage, (Cr) entails that not all meta-sentences find an interpretation in the object language.

8 Tarski (1983c), p. 189. That indeed the use of satisfaction might not be due to the infinitude of sentences does not bear on our argument. For Tarski himself did not realise it in the original German paper, which is the one we are concerned with here.

9 Tarski (1935), p. 307. 
the English version, which was made from the German, ${ }^{10}$ translates 'Erfülltsein' into 'satisfaction' and 'erfüllt' into 'satisfied'.

The notion of 'Erfülltsein' or 'Erfüllung' ('satisfaction') expresses a relation between objects that belong to the variables expressed by that language and the sentential functions of that language. Since sentential functions can include any number of free variables, we have to differentiate the notion of satisfaction. If there is only one variable, satisfaction is a relation between sentential functions and objects; if there are two free variables, satisfaction is a relation between sentential functions and ordered pairs of objects etc. Hence Tarski defines satisfaction recursively too. Furthermore, since satisfaction expresses a relation between objects (or pairs of objects or ...) and sentential functions, we need $(\mathrm{Cr})$ again. To formulate this relation, a language that includes variables of a higher type is needed.

Whereas sentential functions are expressions, i.e. linguistic entities, Tarskian objects can be of various kinds. Depending on whether we are concerned with a theory of truth for physics, mathematics or linguistics, also those objects will differ in their nature. They will be physical, mathematical and linguistic, respectively. So in the case of physics objects presumably would be electrons, photons and the like, and the sentential function ' $x$ is a fermion', for instance, would be satisfied by the object electron but not by the object photon. In the very example Tarski chooses in his famous paper, however, the objects under consideration are not physical. For it is set theory he deals with. Indeed the following quote suggests that Tarski is even reluctant to adopt a notion closely related to physical or external objects, namely 'states of affairs':

If we wished to adapt ourselves to modern philosophical terminology, we could perhaps express this concept by means of the familiar formula: The truth of a sentence consists in its agreement with (or correspondence to) reality. [...]

If, on the other hand, we should decide to extend the popular usage of the term 'designate' by applying it not only to names, but also to sentences, and if we agreed to speak of the designata of sentences as 'states of affairs', we could possibly use for the same purpose the following phrase: A sentence is true if it designates an existing state of affairs.

However, all the formulations can lead to various misunderstandings, for none of them is suffiently precise and clear [...]. It is up to us to look for a more precise expression of our intuitions ${ }^{11}$

A last 'strange' feature of Tarski's theory to be introduced before incorporating all of them into the wider context of his academic background is the fact that the meanings of the expressions in the object language must be known already:

It remains perhaps to add that we are not interested here in 'formal' languages and sciences in one special sense of the word 'formal', namely

10 Wolenski (1997), p. 23.

11 Tarski (1944), p. 343. 
sciences to the signs and expressions of which no meaning is attached. For such sciences the problem here discussed has no relevance, it is not even meaningful. We shall always ascribe quite concrete and, for us, intelligible meanings to the signs which occur in languages we shall consider. ${ }^{12}$

Thus, Tarski's theory of truth and his notion of 'Erfüllung' in particular crucially depend on the language investigated, i.e. the object language, being already interpreted. Hence the meanings of the expressions of the object language must be intuitively given, or to put it differently a self-evident metalanguage is required. Coming back to the example of the language of physics this means that one must know what the object language expressions 'electron' and 'photon' mean before an electron or a photon might occur as an object $\mathrm{x}$ in ' $\mathrm{x}$ is a fermion'.

In summary we could thus say the following: satisfaction holds between sentential functions and objects. We know that the first are expressions and that the second can be varied in nature (linguistic, mathematical, physical etc.). However, we must know the meaning of the names of those objects in the language investigated. Going back to our example: we must know what 'electron' means, where 'electron' is the name for an electron.

Hence, although we do not know about the nature of those objects in general, we know that they must have something I shall call a 'linguistic dimension' (i.e they must have names with self-evident meanings). Therefore in Tarski's theory satisfaction is a relation between two entities, namely sentential functions and objects, which both have a linguistic dimension; and this is true whatever those objects themselves are, whether they are linguistic, mathematical, physical etc.

So much for the introduction to Tarski. Now, I will pick up certain points of Tarski's theory of truth which seem questionable and discuss them in relation to the academic context given in section 1:

(1) Why does Tarski in general assume that we can find out about truth in such a formal, scientific manner of analysis? (section 3)

(2) Going into more detail: how are we to understand Tarski's comment about intuitive or self-evident meaning? How could we grasp meaning before we establish the truth-conditions of sentences? (section 4)

(3) Are there any other theories of truth for which 'satisfaction' or 'Erfüllung' is the central feature? Do they have parallels that might help us in understanding why Tarskian objects can be of various kinds but always have a 'linguistic dimension'? (sections 5 \& 6)

Let's have a look at those questions in turn:

12 Tarski (1983c), p.166-7. 


\section{Philosophy as a Formal, Scientific Enterprise that Allows for}

\section{Metaphysics}

It seems strange to tackle the question of what truth is in the formal way that Tarski does and not in terms of a wider ranging discussion. For one might think that there is more to the nature of truth than just a satisfaction relation in semantics. Here it is worthwhile looking at the tradition in which Tarski was brought up. The Lvov-Warsaw School, as well as sharing certain viewpoints, agreed upon certain important methodological questions. Their aim was not to build up speculative metaphysical systems but to turn philosophy into a science. Twardowski strongly advocated a scientific and formal approach to philosophy although he himself, unlike his students Lesniewski and Lukasiewicz, had no great interest in logic. ${ }^{13}$ Nevertheless, he told his students about new tendencies and ideas in that area. ${ }^{14}$ This explains what Tarski means by 'almost all researchers, who pursue the philosophy of exact sciences in Poland, are indirectly or directly the disciples of Twardowski, although his own work could hardly be counted within this domain.' 15

Tarski himself wrote his $\mathrm{PhD}$ thesis in mathematics with Lesniewski and saw himself as directly influenced by Lukasiewicz, Lesniewski, Kotarbinski and as 'being a mathematician (as well as a logician, and perhaps a philosopher of a sort) ${ }^{6} \cdot{ }^{16}$ For him the application of his mathematical skills to solve philosophical problems was completely natural.

Twardowski himself explicitly states that he became convinced by reading Brentano that the only future for philosophy lies in a scientific attitude and opposition to metaphysical speculation. ${ }^{17}$ Brentano was very suspicious of the metaphysical systems of Kant, Schelling and Hegel and advocated thorough, scientific analyses of particular metaphysical problems. ${ }^{18}$ For him 'vera philosophiae methodus nulla alia nisi scientiae naturalis est.' ${ }^{19}$ His idea of a descriptive psychology which offers much higher reliability than what is normally called science, should be one of the means to reach this aim. He wanted to show that philosophy, if turned into a science in his sense, still had a right of existence. This was often questioned after the fall of Hegelian philosophy in the middle of the nineteenth century and it appears that Brentano's suspicion towards speculative metaphysics was rooted in this context. ${ }^{20}$

Of course, the enterprise of turning philosophy into a science is by no means unique to the Brentano-Polish line of philosophy, but, as we have seen, people here explicitly refer to previous generations. And there are differences between the Brentanian programme of turning philosophy into a science and, for instance, the

13 See Spiegelberg (1982), p. 223; Albertazzi et al. (1996), p. 209.

14 See Albertazzi et al. (1996), pp. 318-9.

15 Cited in Wolenski (1997), p. 22.

16 Tarski (1944), p. 369.

17 See Werle (1989), pp. 4-5.

18 See Albertazzi et al. (1996), p. 209; Spiegelberg (1982), pp. 30-1.

19 Quoted in Kusch (1995), p. 137.

20 See Werle (1989), pp. 28-36. 
programme of the Vienna Circle. The latter, other than Brentano and the Lvov-Warsaw School, assumed an a priori demarcation between science and metaphysics and did not tackle classical metaphysical problems. ${ }^{21}$ A question like 'what is truth?', for instance, as discussed in this paper, was no issue for people of the Vienna Circle. They did not think about such questions in order to build science upon it, they wanted to do science. Thus, it is not solely important that Brentano and the Lvov-Warsaw School (including Tarski) wanted to turn philosophy into a science, but also how they wanted to do it. ${ }^{22}$

Husserl also tried to turn philosophy into a science. ${ }^{23}$ His phenomenology can be viewed as an elaboration of Brentano's descriptive psychology. ${ }^{24}$ Thus again: the characteristic feature is that he allows for metaphysics and held - just like Brentano that nothing that is normally called science really deserves this name. For Husserl it is only his phenomenology that deserves the name 'science' ${ }^{25}$

\section{Self-evident Metalanguage}

The question that arose in connection with Tarski's talk about intuitive meaning was: how can we possibly get a grasp on meaning before we know the truth conditions of that language? It seems a bit odd to give a formal approach to truth in terms of sentential functions etc. on the one hand and to state that we know about the meaning of expressions already on the other.

Again we should look at Tarski’s background: Lesniewski was advertising an intuitionistic formalism according to which every language (including formalised ones) contains expressions with intuitive or self-evident meaning. ${ }^{26}$ This view is opposed to 'standard' formalism which regards languages as systems of marks manipulated by purely syntactic rules; Tarski took over this view: '[...] my personal attitude [...] agrees in principle with that which has found emphatic expression in the writings of $\mathrm{S}$. Lesniewski and which I would call intuitionistic formalism. ${ }^{27}$ He uses the term 'intuitive' in mathematical context when maintaining that definitions are adequate if they are in a sense self-evident, i.e. if 'they in fact grasp the current meaning of the notion as it is known intuitively' ${ }^{28}$

21 See Wolenski (1989), pp. 448-9; also other distinctions between the Lvov-Warsaw School and the Vienna Circle get mentioned there.

22 Here I focused on the Vienna Circle as I thought it to be most familiar to the reader. However, there are also differences with, for instance, the Neo-Kantian programme of turning philosophy into a science: Neo-Kantians engaged in classical epistemological questions and thus differed from both the Lvov-Warsaw School and the Vienna Circle.

23 Throughout this paper I shall be concerned with the Husserl of the Logical Investigations and not with his later transcendental phenomenology. Indeed not all of the claims I am making here would hold for the later Husserl.

24 See Mulligan \& Smith (1985), pp. 627-44.

25 See Bell (1990), pp. 157-61.

26 Lesniewski (1929), p. 78.

27 Tarski (1983a), p. 62.

28 Tarski (1983b), p. 128-9. According to Wolenski (1997), p. 23, the talk about intuitive meanings comes out even more clearly in the Polish original of Tarski's 'The Concept of Truth in Formalized Languages'. 
Intuitive meaning and self-evidence form the core of Brentano's theory of truth. According to him, truth in its strict sense can only be attributed to judgements. ${ }^{29}$ The early Brentano is close to being a straightforward correspondence theorist of truth, although he already sees difficulties: 'To correspond does not mean being the same or being similar. To correspond means being appropriate, fitting, being in agreement, harmonising [...]., ${ }^{30}$

Brentano later elaborates on this so far vague notion of agreement or fitness, when recognising the central problem of a correspondence theory of truth: ${ }^{31}$ 'it is impossible to know about a correspondence, if not both of the things between which the correspondence holds are known to us beforehand. ${ }^{32}$ His worry is that correspondence requests knowledge about the corresponding entities that you must have beforehand, just to be able to see the correspondence. Things cannot get off the ground unless we allow for some surplus knowledge from the very beginning. To solve this problem Brentano refers to self-evidence:

The real guarantee for the truth of a judgement lies in its self-evidence, which it either possesses immediately or which it gets through a proof in connection with other judgements which are immediately self-evident. ${ }^{33}$

Truth then becomes an agreement or fitting between the judgement under consideration and the judgement someone would make if he was able to judge on this matter with selfevidence. This idea is also called the 'impossibility of contradictory self-evidence., ${ }^{34}$ To conclude: unlike in section 3, where it was possible to show a continuity from Brentano to Tarski, here we have a gap in the generation between Lesniewski and Brentano. Nonetheless, in agreement with Wolenski we can state:

Perhaps we could say that the approach to truth in terms of self-evidence, one of the most characteristic features of the Brentanist theory of truth was replaced in Lesniewski by the intuitive self-evidence of meaning. This means that formalized semantics assumes a prior grasping of senses of linguistic expressions: formalized object language assumes an intuitive metalanguage..$^{35}$

It should be noted that the claim here is not that the notion of self-evidence in Brentano's and Tarski's accounts on truth does occur at the very same position. As I have shown, Brentano talks (as well as Husserl, whom I will come to later) about selfevidence in connection with true judgements, whereas for Tarski it is the metalanguage (or to be more precise: the meaning of expressions of the language investigated) that

29 See Brentano (1974), p. 6.

30 Brentano (1974), p. 25 - my translation.

31 See 'Anmerkungen des Herausgebers' in Brentano (1974), p. 172-3.

32 Brentano (1974), p. 137 - my translation.

33 Brentano (1974), p. 137 - my translation.

34 See 'Einleitung' in Brentano (1974), p. xxviii.

35 Wolenski (1997), p. 20. 
must be self-evident - notwithstanding the question of whether the judgements or sentences that are formed by those expressions are true or not.

Surely, to intuitively understand a sentence, which is what Tarski's notion of self-evidence is about, is something different from intuitively knowing whether that sentence is true, which is what Brentano's notion of self-evidence is concerned with. None the less, a comparison between the two notions seems possible because in both cases self-evidence functions to account for a surplus knowledge needed to get the theory of truth started. (A further and more detailed reason why this comparison is legitimate and plausible will be discussed in section 6.)

One could also put it this way: our aim was to make Tarski's claim plausible, the claim that we can know all kinds of meanings of expressions without any knowledge about the truth of the sentences we can build from those expressions. And here it is Tarski's Brentanian tradition which makes it understandable that he uses a concept of self-evidence to serve his need for this 'primary grasp of meaning'. For it is, so to speak, part of this tradition to refer to self-evidence at some core position in an account on truth. Thus, again, a comparison between Brentano's and Tarski's notion of selfevidence is meaningful.

Besides, Tarski's relying on self-evidence also explains the following: one can use his theory of truth to carry out consistency proofs for deductive theories so that only true sentences are provable. Thus, Tarski's theory of truth can be used to establish arithmetic without problems due to Gödel's incompleteness theorem. This is indeed what Tarski purports to have done. ${ }^{36}$ But that is to crack the nut with a sledge hammer. Our premises (i.e. our metalanguage) are logically much stronger than the system whose consistency we are able to proof (i.e. the object language). Allowing such a kind of metalanguage basically means allowing for a complete second order logic to establish arithmetic, and surely that works. One might wonder why a formal logician is claiming such a solution to be appropriate. However, the reason appears obvious: we are talking about a logician brought up in the Brentanian and Lvov-Warsaw tradition.

\section{5. 'Erfüllungs'-theories of Truth}

First I have to make a brief comment about my terminology in what follows. Up to now I have used 'object' only in Tarski's technical sense and I shall keep it that way. This means that by 'object' I refer to those entities that stand in a relation of satisfaction with sentential functions. 'Entity' on the other hand I shall use in a more general sense, so that, for instance, Brentanian judgements as well as Tarskian objects or Tarskian sentential functions are all 'entities' according to my terminology.

It has been argued that there is a continuity of correspondence theories of truth from Brentano to Tarski which link exclusively mental entities or entities with a 'linguistic dimension', as I have been calling it. ${ }^{37}$ Whereas 'standard' correspondence theories of truth link mental entities with physical ones - think of, for instance, Russell

36 See Tarski (1983d), pp. 407-8.

37 See also Smith (1994), Ch. 4.8; Wolenski (1997), passim. 
here - Brentano talks exclusively about judgements being in agreement; and in Tarski's case sentential functions and objects, which can be of various kinds but of which we must know the meaning of their names, stand in a relation of satisfaction. So their theories do not at all - or in case of Tarski at least generally not - deal with anything physical.

This continuity in exclusively linking mental entities or those with a linguistic dimension is indeed striking. It is, however, independent of a notion of correspondence. Tarski's 'Erfüllung' and Brentano's 'agreement' or 'fitness' serve equally well and thus I will refer to them as 'Erfüllungs'-theories of truth.

Another continuity mentioned in the literature is the lack of explicit definitions of truth. Brentano and Twardowski talk about 'true judgements', Lesniewski about 'true sentences' and Tarski about 'the class of true sentences'. ${ }^{38}$ For correspondence theories this seems quite normal. But again, we are in no need of those, for 'Erfüllungs'-theories suit equally well.

Indeed there are advantages of talking in terms of 'Erfüllung': we get rid of the highly controversial talk about Tarski as being a straightforward correspondence theorist. Besides, Poli correctly states that 'one should be wary of attributing a general correspondentist position to all the Brentanians. ${ }^{39}$ And the same goes for Brentano himself. His notion of self-evidence, as we saw in section 4, undermines a straightforward correspondence theory.

To flesh out this talk about 'Erfüllung' further we should look at Husserl's theory of truth. A comparison here seems to be justified because people in the Lvov-Warsaw tradition explicitly refer to Husserl and to how they were influenced by him. For instance, Lukasiewicz followed Husserl in rejecting psychologism and Ajdukiewicz took over parts of Husserl's analysis of meaning. ${ }^{40}$ Tarski too refers to Husserl in his The Concept of Truth in Formalized Languages. This is when he uses Lesniewski's 'semantic categories' which owe their origin to Husserl. ${ }^{41}$ Interestingly, Tarski criticises this notion in the postscript of his article; one might speculate whether something he blindly inherited became suddenly conscious.

According to Husserl we form presentative intentions which are supposed states of affairs. He also calls them meaning intentions, because in them we 'mean' (suppose) that something is the case. Sometimes the state of affairs is not merely meant but is itself present to our mind through experience. We then have a judging possession of this state of affairs itself and judge with self-evidence. This conversion of what was simply meant into something self-evident is called 'Erfüllung' (English translations tend to put 'fulfilment' here instead of 'satisfaction'):

[...] the act of pure meaning, like an goal-seeking intention, finds its fulfilment in the act which renders the matter intuitive. In this transitional experience, the mutual belongingness of the two acts, the act of meaning, on

38 See Wolenski \& Simons (1989), p. 399; Wolenski (1997), pp. 19-20.

39 Albertazzi et al. (1996), p. 343.

40 See Wolenski \& Simons (1989), p. 400.

41 See Tarski (1983c), p. 215; Lesniewski (1929), p. 14; Husserl (1968), Vol 2, pp. 316-21. 
the one hand, and the intuition which more or less corresponds to it, on the other, reveals phenomenological roots. We experience how the same objective item which was 'merely thought of' in symbol is now presented in intuition, and that it is intuited as being precisely the determinate so-and-so that it was at first merely thought or meant to be. ${ }^{42}$

Let me give an example: while sitting on my desk and not looking out of the window I think that the sun is shining. Thus I form a meaning intention. Now I actually look out of the window and I see that the sun is shining. This means that my meaning intention gets fulfilled. My former act of believing that the sun is shining and my act of perceiving become one and I judge self-evidently. ${ }^{43}$

Truth in Husserl's account becomes the correlate of such an act of self-evidence, it is 'the full agreement between what is meant and what is given as such. ${ }^{44}$ A meaning intention becoming an actual experience is true if it gets 'erfüllt' ('fulfilled'), i.e. if it finds an instantiation in an self-evident judgement. ${ }^{45}$ (Thus, also Husserl is talking about truths, namely correlates, rather than truth.)

Also for Husserl, who took his notion of self-evidence over from Brentano, selfevidence plays an important role in talk about truth. ${ }^{46}$ Besides, Husserl does not talk about physical entities and (like Tarski) has a notion of 'Erfüllung' at the core of his theory. Just to remind the English speaking reader here: 'fulfilment' and 'satisfaction' in this context are one and the same word in German. When reading Tarski's 'The Concept of Truth in Formalized Languages', however, one might think that his notion of 'satisfaction' is a purely mathematical one (like in ' 5 satisfies the equation $\mathrm{x}-3=2$ ') and simply does not mean the same as 'fulfilment'. However, to claim that 'satisfaction' is a mathematical notion misses the point for two reasons. First, the German term used in mathematics is also 'Erfüllung'. Second, if Tarski, as a trained mathematician, should have some non common-sense connotations going along with 'Erfüllung' then the same should go for the trained mathematician Husserl.

Using the notion of 'Erfüllung', we can explain why the two entities that stay in this relation of one 'satisfying' or 'fulfilling' the other must both be of the same kind or at least must share some characteristic, i.e. must have a kind of 'common dimension'. While, for a correspondence theory, it makes sense to assume that a mental entity corresponds to a physical one or vice versa, this fails to work for 'Erfüllungs'-theories. It is hard to assume what could be meant by something physical 'erfüllen' something mental or vice versa. Hence, the question why Husserl is talking exclusively about

42 Husserl (1970), Vol 2, p. 694.

43 See Husserl (1968), Vol 3, pp. 121-2.

44 Husserl (1968), p. 122.

45 Husserl distinguishes four notions of truth, but this is of no importance for our purposes (and establishing these dinstinctions would need phenomenological terminology which goes far beyond the scope of this essay).

46 See Spiegelberg (1982), pp. 40-3. Presumably Husserl took the notion of self-evidence from Brentano's lectures on ethics and not on truth - see 'Einleitung' to Brentano (1974), pp. xxviii-xxix. But this doesn't matter to my argument. 
mental entities and why Tarski is talking exclusively about entities with a linguistic dimension (sentential functions and objects of which we know the meaning of their names) finds its counterpart in the notion of 'Erfüllung'. Although this idea fails to go through for Brentano in all detail, his notion of agreement or fitness at least reminds one of something like two pieces of a puzzle fitting together. This, I take it, is rather typical for an 'Erfüllungs-'theory, whereas according to a correspondence theory two separated entities stand in some relation.

Furthermore Brentano, Husserl and Tarski all claim to engage in an Aristotelian programme. Brentano, in several of his writings, starts from the Aristotelian notion of truth being 'adequatio rei et intellectus'. ${ }^{47}$ And Husserl claims that 'where a presentative intention has achieved its ultimate fulfilment by an ideal complete perception, there the real adequatio rei et intellectus is brought about. ${ }^{38}$ For Husserl the mental act of meaning intention is 'intellectus', the act of perception is 'res' and their act of synthesis is 'adequatio'. ${ }^{49}$ Tarski sets himself to give an 'materially adequate and formally correct' $^{50}$ notion of truth which is just another way to talk of 'adequatio rei' and 'adequatio intellectus'; and at another place he remarks that his definition of truth should 'do justice to the intuitions which adhere to the classical Aristotelian conception of truth [...]. ${ }^{51}$

To sum up: by trying to avoid ignorance concerning Brentano's notion of selfevidence and speculation about Tarski's advocation of a correspondence theory, we saw the close relationship between those two theories and also Husserl's. One might even argue that the whole discussion about whether Tarski's account is a correspondence theory is, to a large extent, misleading. First, because one can interpret his account without engaging in that question; second, because what this discussion mainly does is obscure Tarski's relation to his academic background. But to say more, we can even see a reason for this huge debate. The problem seems to lie in Brentano, Husserl and Tarski all referring to Aristotle's concept of truth which is taken to be the classical notion of a correspondence theory. By purporting to remain in an Aristotelian tradition, they themselves obscure the crucial difference between what they are doing and what 'normal' correspondence theorists do. This becomes very clear when looking at how Husserl claims to have realised Aristotle’s notion by, for instance, identifying perception with 'res'.

\section{Towards Semantics}

As shown above, Tarski is trained to tackle philosophical problems in a formal way; meanings are self-evidently given and people around him hold theories of truth which solely deal with non-physical entities. Brentano and Husserl do not refer to physical or external entities because they are talking in terms of intentionality. Hence, for them any

47 See Brentano (1974), pp. 3 ff., $131 \mathrm{ff} ., 137 \mathrm{ff}$.

48 Husserl (1968), Vol 3, p. 118 - my translation.

49 See Bell (1990), p. 146.

50 Tarski (1983c), p. 152.

51 See Tarski (1944), p. 342. 
mental phenomenon (including judgements which is what they are concerned with in their theories of truth) is already directed towards something. ${ }^{52}$ Also Tarski can do without physical entities and in his famous paper, where he deals with set theory, he indeed does without them - notwithstanding the fact that for the particular example of a language of physics the objects of that language would, of course, be physical. This is because he puts things in assertions about language, which itself has meaningful expressions already incorporated in it, namely the sentential functions and what I have called the 'linguistic dimension' of the objects of the language investigated.

At this point one could simply state what in the literature has been called the Brentano-Chisholm thesis, according to which the semantic properties of a language reflect intentional properties of the mind. ${ }^{53}$ If we take this thesis to be true, then in the present context this suggests nothing else but that Tarski's theory of truth reflects Brentano's and Husserl's theories of truth. Thus we see how the notions of 'Erfüllung' in Husserl and Tarski could be related.

However, let me try to be a bit more specific about how intentionality dressed linguistically could lead to semantics quite easily - especially given that this connection is acknowledged in the Brentanian tradition itself. At the centre of the link between intentionality and semantics one normally finds the idea that the use of language is a human activity. Husserl is an example, here. For him linguistic acts get their referential power from the intentionality of acts of thought. Thus, for Husserl language is meaningful (and therefore has semantic properties) only in so far as it expresses intentions. ${ }^{54}$ Another example of how to get from judgements, which are intentional, to sentences, which are linguistic, is provided by Twardowski in his paper 'Action and Products'. ${ }^{55}$

Instead of going into further detail about Husserl and Twardowski here, the following 'thought experiment' might be more helpful in showing the close connection between a semantic and a phenomenological theory of truth (please note that the following is not offered as having any historical significance):

Starting from Tarski's theory, assume that one is willing to modify it in a Husserlian way. As I have shown, Tarski assumes an intuitive metalanguage, i.e. there is a self-evidence relation with respect to meaning between names of objects and objects themselves. Additionally, Tarski relies on a relation of fulfilment between objects and sentential functions. Now, Tarskian objects can be physical (although as we have seen, in general they will not be), but Husserl is not concerned with external entities whatsoever - our 'Husserlian modification' had better free us from these objects. However, without the objects the two relations in Tarski's account would melt into one. The self-evidence relation and the fulfilment relation would unite. As shown above, such a relation of self-evidence concerning fulfilment is exactly the kind of relation Husserl brings forward in his theory.

52 See Sajama \& Kamppinen (1987), p. 2.

53 See Wolenski (1997), p.23; Sandford (1997), passim.

54 See Husserl (1968), Vol.2, Investigations I \& V.

55 This paper also gets discussed in Wolenski (1997), p. 16. 
This also explains, what (for different reasons) we assumed in section 4: that one may compare Husserl's or Brentano's notion of self-evidence with Tarski's. For according to this thought experiment we can get the former from the latter via this 'Husserlian modification'.

Thus, it is for this close connection to intentionality that semantics emerged among Brentanian scholars in Poland and not, for instance, in the philosophy of Russell or the Vienna Circle. The latter had no 'intentional background', they thought about the world outside and tried to get along with classical correspondence theories of truth instead of 'Erfüllungs-'theories.

\section{Conclusion}

To conclude, I will briefly summarise the parallels I have drawn between phenomenology and logical semantics and indicate something of their philosophical significance.

In this essay I have shown several connections between the theories of truth proposed by Brentano, Tarski and Husserl. More specifically I have been concerned with showing how self-evidence is a crucial feature for all of them, why and how they all talk about 'truths' rather than truth, and why it is that they can deal without the physical entities which seem so central for correspondence theories of truth. I have shown some of these features, together with a characteristic scientific attitude towards philosophy, to be shared by phenomenologists and members of the Lvov-Warsaw school more generally. The linkage between intentionality and semantics has been emphasised and I have argued that staying in a phenomenological framework quite straightforwardly leads towards a semantic theory of truth. Moreover, in this essay I have shown how Brentano, Husserl and Tarski all see themselves as bringing about Aristotle's programme of a theory of truth, why it is that these claims are somewhat misleading and how their approaches towards truth can be nicely captured by adopting the term 'Erfüllung', used by both Husserl and Tarski.

Thus, the contribution of this paper to questions of general philosophical interest is threefold:

First, I have shown that the linkage between intentionality and semantics could be provided by viewing language as a human activity and illustrated this link by appealing to a thought experiment. Thus, different ways for getting from acts/judgements to sentences have been suggested. This means that we have seen how two main areas of research, namely the philosophy of mind and the philosophy of language, could be connected.

Second, the results of this paper allow us to put Tarski's and Husserl's approaches in their proper place. As I have already mentioned in section 1, debates about whether Tarski is a correspondence theorist or not are still going on without clear results. Indeed more or less the same is true for Husserl; here again the question of how 
much of a correspondence theorist Husserl might be is difficult to answer. ${ }^{56}$ Thus, the comparison between Husserl and Tarski provided here might help the scholarship on both sides to a better understanding. For this paper provides us with a new starting point called 'Erfüllung' which is common to both Husserl and Tarski and which hopefully helps reorientate future debates upon their theories of truth.

Third, all this points to a more general philosophical concern, namely that the distinction some people tend to make between Continental philosophy (as represented by Brentano and Husserl here) and analytic philosophy (as represented by Tarski) indeed is not helpful at all. The fact that these two traditions share several important problems and concerns has been shown by influential works of, for instance, Hintikka, Tugendhat and Kusch. ${ }^{57}$ In particular their studies on language and truth have suggested that to gain relevant philosophical insights, one would do best to abandon this analytic/ Continental dichotomy in one's philosophical thinking.

The same is true for the theories dealt with in this paper. I emphasised the common tradition in which Husserl and Tarski grew up, established several parallels and opened up a new class called 'Erfüllungs'-theories of truth into which both Husserl's and Tarski's approach falls. Thus, this new category puts together theories of truth from within analytic and Continental philosophy and it helps to gain a better understanding of both of them. Therefore, in being guided by the commonalities shown and ignoring the pretended gap between Continental and analytic philosophy we are lead to some new and fruitful insights. Hence, the more general aim of this paper is to contribute to a growing body of work that seeks to reject the analytic/Continental distinction as a model for understanding philosophical traditions. ${ }^{58}$

\section{References}

Albertazzi, L., Libardi, M., and Poli, R. (eds.) (1996): The School of Franz Brentano. Dordrecht: Kluwer. Bell, D. (1990): Husserl. London: Routledge.

Brentano, F. ([1874], 1973): Psychologie vom empirischen Standpunkt, 2 vol. Hamburg: Felix Meiner.

Brentano, F. ([1930], 1974): Wahrheit und Evidenz. Hamburg: Felix Meiner.

Husserl, E. ([1900/1], 1968): Logische Untersuchungen, 3 Vol. Tübingen: Max Niemeyer.

Husserl, E. ([1900/1], 1970): Logical Investigations, 2 Vol. London: Routledge.

Kusch, M. (1989): Language as Calculus vs. Language as Universal Medium: A Study in Husserl, Heidegger and Gadamer. Dodrecht: Kluwer.

Kusch, M. (1995): Psychologism. London: Routledge.

Lesniewski, S. (1929): 'Grundzüge eines neuen Systems der Grundlagen der Mathematik', in Fundamenta Mathematicae 14, pp. 1-81.

Mulligan, K., and Smith, B. (1985): 'Brentano and the Ontology of Mind', in Philosophy and Phenomenological Research 45, pp. 627-44.

Sajama, S., and Kamppinen, M. (1987): A Historical Introduction to Phenomenology. London: Croom Helm.

56 See, for instance, Kusch (1989), Part II, Ch. 3.5.

57 See Kusch (1989), Part I. The relevant works by Hintikka and Tugendhat get mentioned there, too.

58 I am grateful to Martin Kusch and Matthew Ratcliffe for reading earlier drafts of this paper. 
Sandford, D. H. (1997): ‘Chisholm on Brentano's Thesis', in The Library of Living Philosophers: The Philosophy of Roderick M. Chisholm, L. E. Hahn (ed.). Chicago: Open Court, pp. 201-14.

Smith, B. (1994): Austrian Philosophy - The Legacy of Franz Brentano. La Salle \& Chicago: Open Court. Spiegelberg, H. (1982): The Phenomenological Movement: A Historical Introduction. The Hague: Martinus Nijhoff.

Tarski, A. ([1930], 1983a): 'Fundamental Concepts of the Methodology of the Deductive Sciences', in Logic, Semantics, Metamathematics, A. Tarski. Indianapolis: Hackett, pp. 60-109.

Tarski, A. ([1931], 1983b): 'On definable Sets of Real Numbers', in Logic, Semantics, Metamathematics, A. Tarski. Indianapolis: Hackett, pp. 110-42.

Tarski, A. ([1933], 1935): 'Der Wahrheitsbegriff in den formalisierten Sprachen’, in Studia Philosophica 1, pp. 261-405.

Tarski, A. ([1933], 1983c): 'The Concept of Truth in Formalized Languages', in Logic, Semantics, Metamathematics, A. Tarski. Indianapolis: Hackett, pp. 152-278.

Tarski, A. ([1936], 1983d): 'The Establishment of Scientific Semantics', in Logic, Semantics, Metamathematics, A. Tarski. Indianapolis: Hackett, pp. 401-8.

Tarski, A. (1944): 'The Semantic Conception of Truth and the Foundations of Semantics', in Philosophy and Phenomenological Research 4, pp. 341-75.

Twardowski, K. ([1894], 1982): Zur Lehre vom Inhalt und Gegenstand der Vorstellungen - Eine psychologische Untersuchung. Munich: Philosophia.

Werle, J. M. (1989): Franz Brentano und die Zukunft der Philosophie. Amsterdam: Rodopi.

Wolenski, J. (1989): 'The Lvov-Warsaw School and the Vienna Circle', in The Vienna Circle and the Lvov-Warsaw School, K. Szaniawski. Dordrecht: Kluwer, pp. 443-53.

Wolenski, J. (1997): 'Theories of Truth in Austrian and Polish Philosophy'. Http://www.fmag.unict.it/PolPhil/LvovWarsaw/WolTruth.html.

Wolenski, J., and Simons, P. (1989): 'De Veritate: Austro-Polish Contributions to the Theory of Truth from Brentano to Tarski', in The Vienna Circle and the Lvov-Warsaw School, K. Szaniawski (ed.). Dordrecht: Kluwer, pp. 391-442.

This postprint was prepared by Hannah Mahé Crüsemann. 